\title{
Leveraging Innovation Resources for Modular Products under Open Innovation Scenarios Using Fuzzy Distance Method
}

\author{
Hai-jun Wang (D) and Chao-hui Shu \\ School of Management, Shenyang University of Technology, Shenyang 110870, China \\ Correspondence should be addressed to Hai-jun Wang; hj.wang@sut.edu.cn
}

Received 3 July 2020; Revised 10 August 2020; Accepted 29 August 2020; Published 14 September 2020

Academic Editor: Lifei Chen

Copyright (c) 2020 Hai-jun Wang and Chao-hui Shu. This is an open access article distributed under the Creative Commons Attribution License, which permits unrestricted use, distribution, and reproduction in any medium, provided the original work is properly cited.

\begin{abstract}
In an open innovation environment, it is meaningful for manufacturing enterprises targeting global markets to integrate qualified innovation resources. In this paper, the linkage between product modularity and open innovation is first discussed, revealing a role that modular product architecture plays in linking enterprises' innovation requirements and innovation resources as external innovation inputs. Next, indices for evaluating external innovation resources are developed. An evaluation method based on fuzzy distance is then proposed, which is intended to select optimal resources for the core modules of modular product architecture. A modular product of Haier Group is used as a typical case to verify the proposed method. Consistent evaluation results of innovation resources are achieved for different decision-making attitudes. Another finding regarding the case enterprise is that the resource management mechanisms it employs lead to a win-win cooperative relationship with its partners.
\end{abstract}

\section{Introduction}

As the industrial chain is growing more open than ever, the traditional vertical integration model where a product is manufactured by a single enterprise independently is no longer the trend. The significance of an open innovation system for corporate technical innovations is becoming unquestionably evident [1]. In their attempts at improving market competitiveness with rapidly manufactured and lowcost products or services, a growing number of enterprises have crossed their organizational border for technical innovations and embarked on joint R\&D activities by taking advantage of external resources [2]. Against this backdrop, an external resource network consisting of universities, scientific research institutes, and suppliers now evolves as an increasingly important source for corporate innovations.

In the open innovation theory of Chesbrough [3], an enterprise may seek innovations by introducing and absorbing diverse external resources. The significance of an open innovation system for corporate technical innovations has been well documented $[1,2]$. As an example, statistics show that, in the period from 2001 to 2006 , about $50 \%$ of the products of Procter \& Gamble stemmed from cooperative research and development with its external partners.

Schmitt pointed out that, in an interdependent relationship between supply and demand sides, the establishment of a long-term mechanism contributes substantially to resource sharing and continued coordination [4]. However, research gaps exist regarding reasonable selection and integration of heterogeneous module innovation resources. In particular, issues due to the subjective and ill-targeted introduction of external partner resources and homogeneity of such resources can be serious. Furthermore, there is a general lack of research on the design of an effective mechanism for managing evaluated and selected partners.

In addition, with the development of economic globalization, large manufacturing enterprises involved in global markets pursue a more professional division of labor and coordination. Complicated products are decomposed into multiple functional modules, while external innovation resources such as design houses and modular suppliers are integrated into corresponding stages of product design, procurement, manufacturing, and service with the assistance of standardized module interfaces, thus forming a modular 
innovation network. Based on the above discussion, this study explores an effective method, aiming at leveraging innovation resources for modular products of large manufacturing enterprises under open innovation scenarios. The remainder of this article is organized as follows. Section 2 presents a method of evaluating and selecting innovation resources. To verify such method, Section 3 introduces a case study of a large Chinese manufacturing enterprise. Section 4 concludes this paper.

\section{Method}

2.1. Modularity and Open Innovation. Modularity refers to a process where a complicated system is broken down into a number of modules with standard interfaces [5]. The key of modularity is to incorporate users' demands into a product design process and to generate modular products [6, 7]. Modular product architecture (MPA) is a unified form of architecture with loosely coupled modules as the basic elements. MPA allows enterprises to realize product modularity, to decompose corresponding innovation tasks, and to assign individual innovation resources to such tasks (Figure 1). In this way, MPA can play the role of linking the demand and supply sides of innovation [8]. Through the coordination role of the standardized interface, the interdependence between technical modules and resources they rely on can be reduced [9].

In an open innovation environment driven by product modularity, the supply and demand sides, as innovation stakeholders, are able to rapidly align their new innovation tasks and requirements with each other based on "transparent design rules" of modules. Meanwhile, they can eliminate barriers at innovation interfaces possibly resulting from information asymmetries and subjective differences. This in turn leads to optimal quantity and quality of external resources as well as reduced cost of communication and coordination.

2.2. Indices for Evaluating Module Innovation Resources. For enterprises implementing product modularity, there are multiple possible forms of collaboration with external resources like "university-enterprise", "research institute-enterprise", and "supplier-enterprise". Such collaboration is expected to promote enterprise innovation competitiveness through the interaction of elements such as knowledge and technology [10]. By referring to previous studies about categories of innovation resources under open innovation scenarios $[3,11]$, we further classify innovation resources into nine primary types: university (M1), research institute (M2), strategic supplier (M3), testing laboratory (M4), technology innovation agent (M5), industrial association (M6), consulting firm (M7), venture capital firm (M8), and individual expert (M9). In particular, strategic suppliers are module suppliers that can not only respond to enterprises' module procurement requirements in a timely way but also take part in early research and development of these enterprises.
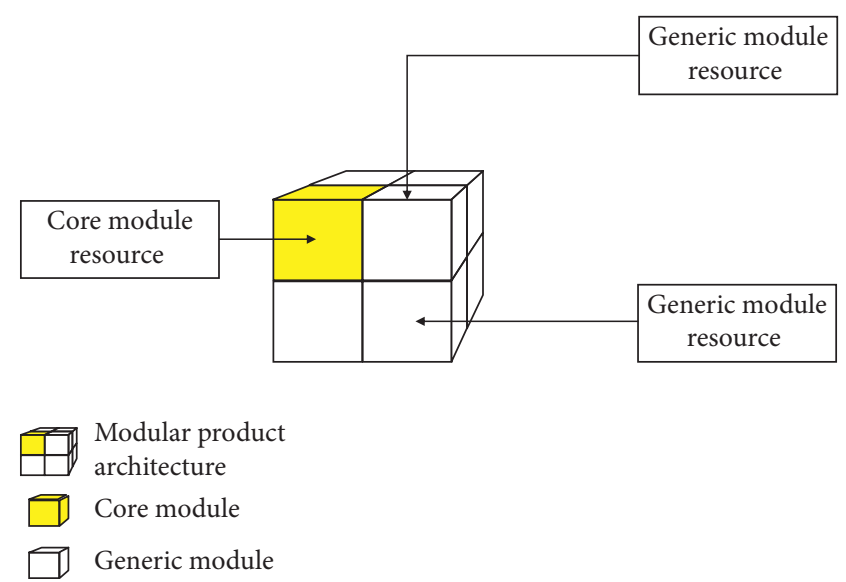

FIgURE 1: Linkage between innovation resources and modular product architecture.

Scholars have demonstrated that basic qualification, performance, and availability are critical for the evaluation and selection of external resources [12]. Technological innovation ability and resource complementarity are regarded as key indicators for assessing partners, and coordination between external resources and an enterprise is an important factor affecting the latter's innovation performance $[13,14]$. Shaikh pointed out that the selection of open innovation resources is even more complicated [15], and the evaluation of open innovation resources should pay more attention to value creation. In addition, knowledge matching and complementarity between external resources and an enterprise also play an important role in improving the latter's product innovation performance [16].

According to our survey and observation, the evaluation and selection of external resources by an enterprise implementing product modularity are not merely based on technology innovation and organization management aspects. The abilities of external resources to improve the performance of the module value chain need to be considered as well. Hence, this paper defines evaluation indices for external innovation resources, including basic qualification and reputation (P1), technology innovation ability (P2), complementarity (P3), ability to perform a contract (P4), integration difficulty (P5), management and control difficulty (P6) (P5 describes the difficulty to integrate external resources into open innovation activities, while P6 is a measure of the difficulty for an enterprise to coordinate with resources in a cooperative innovation project), cost performance (P7), ability to provide value-added services (P8), and ability to manage and control subresources (P9).

\subsection{Evaluation and Selection of Module Innovation Resources.} Considering the nature of the evaluation and selection of strategic innovation resources for core modules (systems), a fuzzy method is usually adopted for ranking comprehensive performances of candidate resources. However, there exist certain shortcomings of traditional fuzzy ranking methods $[17,18]$ : (1) their calculation processes are complex; (2) they are sometimes in conflict with human intuition or lack 
discrimination; (3) the information of decision elements like the weight used for modeling is accurate, which is not the case in practice. To address these shortcomings, this paper proposes a novel fuzzy ranking method featuring a fuzzy distance comparison. The method includes the following specific steps.

\subsubsection{Definition of Evaluation Indices and Fuzzy Mem-} bership Function. The fuzzy linguistics made by evaluation experts is converted to triangular fuzzy numbers. For instance, five levels of fuzzy linguistics, i.e., very low (VL), low $(\mathrm{L})$, moderate $(\mathrm{M})$, high $(\mathrm{H})$, and very high $(\mathrm{VH})$, can be employed to describe the importance of different indices (Figure 2). In this regard, a triangular fuzzy function can be used to express the linguistics of such fuzzy evaluations. For example, an index with an importance level of moderate (M) may be denoted by a triangular fuzzy number $(0.2,0.5,0.8)$. Next, seven levels of fuzzy linguistics, i.e., very good (VG), good $(G)$, relatively good (RG), moderate $(M)$, relatively poor (RP), poor (P), and very poor (VP), can be employed to evaluate the performance of external module innovation resources (Figure 3).

2.3.2. Evaluating Fuzzy Weights and Each Candidate Resource. It is assumed that there are $M$ external module innovation resources to be rated and $N$ experts engaged in rating. By using $a_{i j}^{k}$ to indicate a rating value assigned by an expert $E_{k}(k=1,2, \ldots, N)$ to an external module innovation resource $\mathrm{M} i$ for the index $P_{j}(j=1,2, \ldots, 9)$, the fuzzy evaluation matrix $\mathbf{A}$ can be expressed as

$$
\mathbf{A}=\left[a_{i j}\right]_{M \times 9}=\left[\begin{array}{cccc}
a_{11} & a_{12} & \cdots & a_{19} \\
a_{21} & a_{22} & \cdots & a_{29} \\
\cdots & \cdots & \cdots & \cdots \\
a_{M 1} & a_{M 2} & \cdots & a_{M 9}
\end{array}\right],
$$

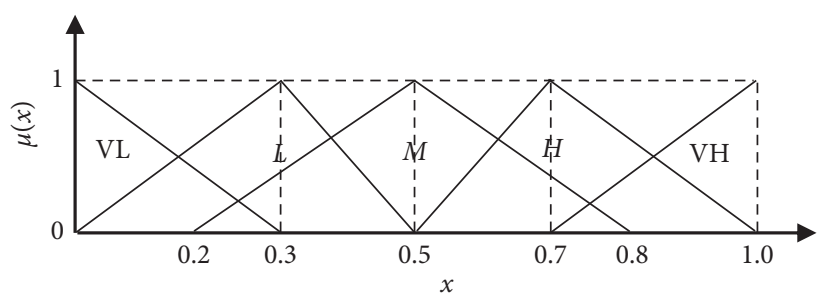

Figure 2: Membership functions for ranking indices.

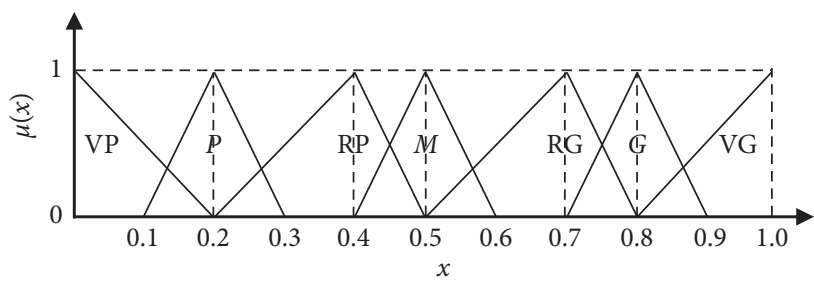

FIgURE 3: Membership functions for ranking resources.

where $a_{i j}$ is a comprehensive evaluation fuzzy number of the external module innovation resource $M_{i}(i=1,2, \ldots, M)$ for the index $\mathrm{P}_{j}$. Naturally, there is a conversion relation between $a_{i j}$ and $a_{i j}^{k}$ :

$$
a_{i j}=\frac{1}{N} \otimes\left(a_{i j}^{1} \oplus a_{i j}^{2} \oplus \cdots \oplus a_{i j}^{N}\right) .
$$

A combination of significance values assigned by different experts to the index gives the fuzzy weight factor $\mathbf{B}=\left\{b_{1}, b_{2}, \ldots, b_{9}\right\}$. On this basis, the final evaluation results of all candidate resources can be derived by multiplying the fuzzy evaluation matrix $\mathbf{A}$ by the fuzzy weight vector $\mathbf{B}$ of the index:

$$
R=A \otimes B^{T}=\left[\begin{array}{c}
r_{1} \\
r_{2} \\
\vdots \\
r_{M}
\end{array}\right]=\left[\begin{array}{c}
a_{11} \otimes b_{1} \oplus a_{12} \otimes b_{2} \oplus \cdots \oplus a_{19} \otimes b_{9} \\
a_{21} \otimes b_{1} \oplus a_{22} \otimes b_{2} \oplus \cdots \oplus a_{29} \otimes b_{9} \\
\vdots \\
a_{M 1} \otimes b_{1} \oplus a_{M 2} \otimes b_{2} \oplus \cdots \oplus a_{M 9} \otimes b_{9}
\end{array}\right],
$$

where $r_{i}$ is the fuzzy rating value assigned to an external module innovation resource $\mathrm{M} i, r_{i}=a_{i j} \times b_{j}, b_{j}$ is the fuzzy weight value for index $\mathrm{P} j$, and $\otimes$ and $\oplus$ are fuzzy operators. The fuzzy sum and product of triangular fuzzy numbers $\widetilde{A}=$ $\left(a_{\mathrm{L}}, a, a_{\mathrm{R}}\right)$ and $\widetilde{B}=\left(b_{L}, b, b_{R}\right)$ can be expressed as

$$
\left\{\begin{array}{l}
\widetilde{A} \oplus \widetilde{B}=\left(a_{\mathrm{L}}, a, a_{\mathrm{R}}\right) \oplus\left(b_{\mathrm{L}}, b, b_{\mathrm{R}}\right)=\left(a_{\mathrm{L}}+b_{\mathrm{L}}, a+b, b_{\mathrm{R}}+b_{\mathrm{R}}\right), \\
\widetilde{A} \otimes \widetilde{B}=\left(a_{\mathrm{L}}, a, a_{\mathrm{R}}\right) \otimes\left(b_{\mathrm{L}}, b, b_{\mathrm{R}}\right)=\left(a_{\mathrm{L}} b_{\mathrm{L}}, a b, a_{\mathrm{R}} b_{\mathrm{R}}\right) .
\end{array}\right.
$$

2.3.3. Ranking Each Candidate Resource Using Fuzzy Distance Measurement Method. Since the above evaluation assignment process for external module innovation resources still leads to fuzzy numbers, it is not yet possible to determine the final ranking of module innovation resources. A fuzzy distance measurement method is, therefore, adopted for further comparison of the fuzzy numbers [19]. The sequence of fuzzy numbers is determined by comparing the distance from every fuzzy number to predefined maximum and minimum 
distinguishing points. The fuzzy number closest to the maximum distinguishing point $\left(D_{\max }\right)$ and most distant from the minimum distinguishing point $\left(D_{\min }\right)$ ranks first in the sequence and is regarded as the strategic innovation resource for the core module (system) of an enterprise in further cooperation.

Following the theory of fuzzy distance measurement method [19], we can define a distance between two random fuzzy numbers (A and $\mathbf{B}$ ) as

$$
D^{2}(A, B, f)=\int_{0}^{1}\left\{\left[\left(\frac{A_{L}(\alpha)+A_{U}(\alpha)}{2}\right)-\left(\frac{B_{L}(\alpha)+B_{U}(\alpha)}{2}\right)\right]^{2}+\frac{1}{3}\left[\left(\frac{A_{L}(\alpha)+A_{U}(\alpha)}{2}\right)^{2}+\left(\frac{B_{L}(\alpha)+B_{U}(\alpha)}{2}\right)^{2}\right]\right\} \times \frac{f(\alpha) \mathrm{d} \alpha}{\int_{0}^{1} f(\alpha) \mathrm{d} \alpha}
$$

where $A_{L}(\alpha), A_{U}(\alpha), B_{L}(\alpha)$, and $B_{U}(\alpha)$ represent an $\alpha$ cut set interval of random fuzzy numbers $A$ and $B$, and

$f(\alpha)=\alpha^{\tau}((0 \leq \alpha \leq 1)$ represents a weight function, and it is a continuous positive function defined in the interval $[0,1]$.

Hence, $D_{\max }$ and $D_{\min }$, i.e., the distances from any triangular fuzzy number to the maximum distinguishing point ( $\max )$ and minimum distinguishing point (min), can be derived:

$$
\begin{aligned}
D^{2}(r, M)= & \left(r_{2}-M\right)^{2}+\frac{1}{\tau+2}\left(r_{2}-M\right)\left[\left(r_{3}+r_{1}\right)-2 r_{2}\right] \\
& +\frac{2}{3(\tau+2)(\tau+3)}\left[\left(r_{3}-r_{2}\right)^{2}+\left(r_{2}-r_{1}\right)^{2}\right] \\
& -\frac{2}{3(\tau+2)(\tau+3)}\left[\left(r_{3}-r_{2}\right)\left(r_{2}-r_{1}\right)\right],
\end{aligned}
$$

where $r$ is a triangular fuzzy number to be rated, $r=\left(r_{1}, r_{2}, r_{3}\right), M$ is the maximum or minimum distinguishing point, and $\tau$ is the weight coefficient.

Different $f(\alpha)$ values correspond to different weights used during the calculation of fuzzy distance. For example, when $\tau=1$, a larger value of $\alpha$ in $[0,1]$ corresponds to a higher weight assigned to it. When $\tau=0$, all $\alpha$ values in $[0,1]$ have the same weight. Different $\tau$ values reflect different decision-making attitudes. If a decision maker tends to be neutral, then, $\tau=1$ is more reasonable. $\tau>1$ is preferred for a conservative decision maker, and $\tau=0$ or a decreasing function is preferred for an aggressive decision maker. The maximum and minimum distinguishing points can be derived from the following equation:

$$
\begin{aligned}
& \max (I) \geq \sup \left(\bigcup_{i=1}^{I} s\left(\widetilde{A}_{i}\right)\right), \\
& \min (I) \leq \inf \left(\bigcup_{i=1}^{I} s\left(\widetilde{A}_{i}\right)\right) .
\end{aligned}
$$

Based on the above analysis, the following characteristics of the proposed innovation resource evaluation method based on fuzzy distance measurement can be observed. First, compared with traditional evaluation and ranking methods, e.g., the analytic hierarchy process (AHP), the calculation process of the proposed method is simpler and visualized. Second, various $t$ values can reflect different decision attitudes, thereby leading to good robustness and flexibility. Finally, fuzzy linguistics are used to evaluate the weight of each index. By combining the performance of candidate innovation resources, such linguistics are more in line with real situations.

\section{Case Study and Results}

3.1. Case Background. Haier Group, a typical Chinese manufacturing enterprise evolving rapidly in the time of Reform and Opening, is selected for a case study to verify the proposed method. There are four major reasons for selecting Haier as the case sample. (1) Haier is now a leader in the Chinese home appliance industry, and also one of the large pioneering Chinese enterprises that have strategically built their worldwide R\&D, production, marketing, and sales networks. (2) Despite its rapid development in recent decades, Haier realizes that it has become impossible to meet ever-increasing product design complexity and customer demands by relying only on its own R\&D capabilities. Consequently, Haier adopts an open innovation strategy to exploit innovation potential via external partners. Meanwhile, Haier has established an open innovation platform, Haier Open Partnership Ecosystem (HOPE), on which it interacts with external resources to come up with innovative solutions and fulfill global users' requirements. (3) In 2011, Haier switched from traditional component design to a product modularity model for its large home appliance lines. Modularity has, thus, become a key pillar for the company to leverage product innovations and pursue business model transformations.

The Chinese air-conditioning industry has entered a highly competitive stage in recent years. On the one hand, the tasks of energy conservation and emission reduction are demanding, and real estate regulation and control policies suppress further expansion of the industry. With the release of energy-saving product subsidy policies, the production cost of air conditioners is gradually rising. On the other hand, too many homogeneous Chinese air-conditioning products lacking technological innovation are competing more intensely than before in the market. Realizing that the in-house R\&D force alone would no longer completely meet global customer needs, Haier CEO 
Zhang Ruimin calls for a move from a closed organization to an open one.

Our analysis involves a high-end air conditioner product (T-AC) of Haier Group that features a modular design. This product is a response to a survey of over 600,000 consumers. It is mainly intended to address issues or needs related to airconditioning diseases, cold air, natural air, and remote control.

3.2. Overview of Case Product Modularity. The modular product architecture of T-AC was created using the MFD methodology given by Ericsson and Erixon [5] and is composed of 28 modules with standardized interfaces. To further promote commonality among different modules and optimize the number of external innovation resources, Haier worked out seven module systems based on the functional and supply chain correlations among modules (Figure 4). Therefore, the modular product architecture can be depicted as seven module systems plus ten individual modules. On top of that, the core module (system) within the modular product architecture is defined according to Haier's technological and marketing strategies as well. The integration of external innovation resources for the core module (system) was well considered.

Being regarded as one core module (system), the airsupplying module system is closely related to air output, air supply distance, and air supply range of T-AC (Figure 5). Due to product modularity, Haier released modular interface standards with external innovation resources without disclosing too much detailed information such as technical specifications, drawings, and inspection standards. Accordingly, technical secrets and intellectual properties of
T-AC as well as its modules (systems) have been well protected, though it was necessary to design proper methods to integrate qualified, competent, and suitable external innovation resources during development.

\subsection{Evaluation and Selection of Module Innovation Resources.} With the evaluation method described in Section 2.2, an optimum module innovation resource is selected from the candidate resources $\left(M_{i}, i=1,2, \ldots, 9\right)$ collected from around the world and made available on the HOPE (Haier Open Partnership Ecosystem) platform. In this process, the participating evaluators first assign a value to each index based on five levels of fuzzy language: very low (VL), low (L), moderate $(\mathrm{M})$, high $(\mathrm{H})$, and very high $(\mathrm{VH})$. Ratings of the significance of the module innovation resource indices by three experts are given in Table 1. The triangular fuzzy numbers corresponding to the fuzzy language are $\mathrm{VL}=(0,0$, $0.3), L=(0,0.3,0.5), M=(0.2,0.5,0.8), H=(0.5,0.7,1.0)$, and $\mathrm{VH}=(0.7,1.0,1.0)$.

Seven levels of fuzzy language, i.e., very good (VG), good $(\mathrm{G})$, relatively good $(\mathrm{RG})$, moderate $(\mathrm{M})$, relatively poor $(\mathrm{RP})$, poor $(\mathrm{P})$, and very poor (VP), are then used by three experts to evaluate each innovation resource for different indices. The fuzzy evaluation matrix of external modular resources based on the evaluation by three experts is given in Table 2. The triangular fuzzy numbers of fuzzy language are

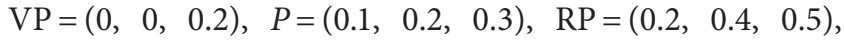
$M=(0.4,0.5,0.6), \mathrm{RG}=(0.5,0.7,0.8), G=(0.7,0.8,0.9)$, and $\mathrm{VG}=(0.8,1.0,1.0)$.

The fuzzy rating values of all module innovation resources can be derived from (1)fd1:

$$
\mathbf{R}=\left(\widetilde{r}_{1}, \widetilde{r}_{2}, \ldots, \widetilde{r}_{9}\right)=\left(\begin{array}{c}
(1.9056,3.9989,6.2822),(1.8867,3.7056,5.8456), \\
(1.9167,4.3467,6.7478),(1.6433,3.8700,6.3100), \\
(0.8422,2.1733,4.1178),(1.4956,2.5233,4.5167), \\
(1.6833,2.7867,4.4400),(1.4678,3.5278,5.8344), \\
(1.6211,3.4600,5.8689)
\end{array}\right)
$$

By selecting $\tau=0,1 / 2,1,2$, the ranking values of all external module innovation resources can be obtained, as shown in Table 3. It can be seen from Figures 6-9 that for different decision-making attitudes (i.e., at different values of $\tau)$, the distances from the evaluation fuzzy numbers for M1-M9 to maximum and minimum distinguishing points are consistent. The fuzzy rating number of module innovation resource M5 (strategic suppliers) is closest to the maximum distinguishing point and most remote to the minimum distinguishing point. M5 can, therefore, be determined as the optimum module innovation resource.

During the cooperation with a selected strategic supplier (a bid winner), Haier implemented resource management mechanisms. First, a contract-binding mechanism was used to regulate the rights and responsibilities of both parties, leading to well-defined delivery times, prices, and supporting services for innovative air supply module services. Second, a dynamic optimization mechanism was used to keep the strategic supplier competitive, driving its capability upgrading. Third, Haier focused on a practical incentive mechanism called "big resources in exchange for big resources." For example, large-volume module purchase orders were placed to stimulate adequate innovation inputs from the strategic supplier during its cooperation with Haier.

Driven by these mechanisms, the open innovation network was operated in a self-organized way. Following the implementation of its corporate transition strategy in recent years, Haier has concluded that it must rely on such operation mechanisms to improve the quality and 


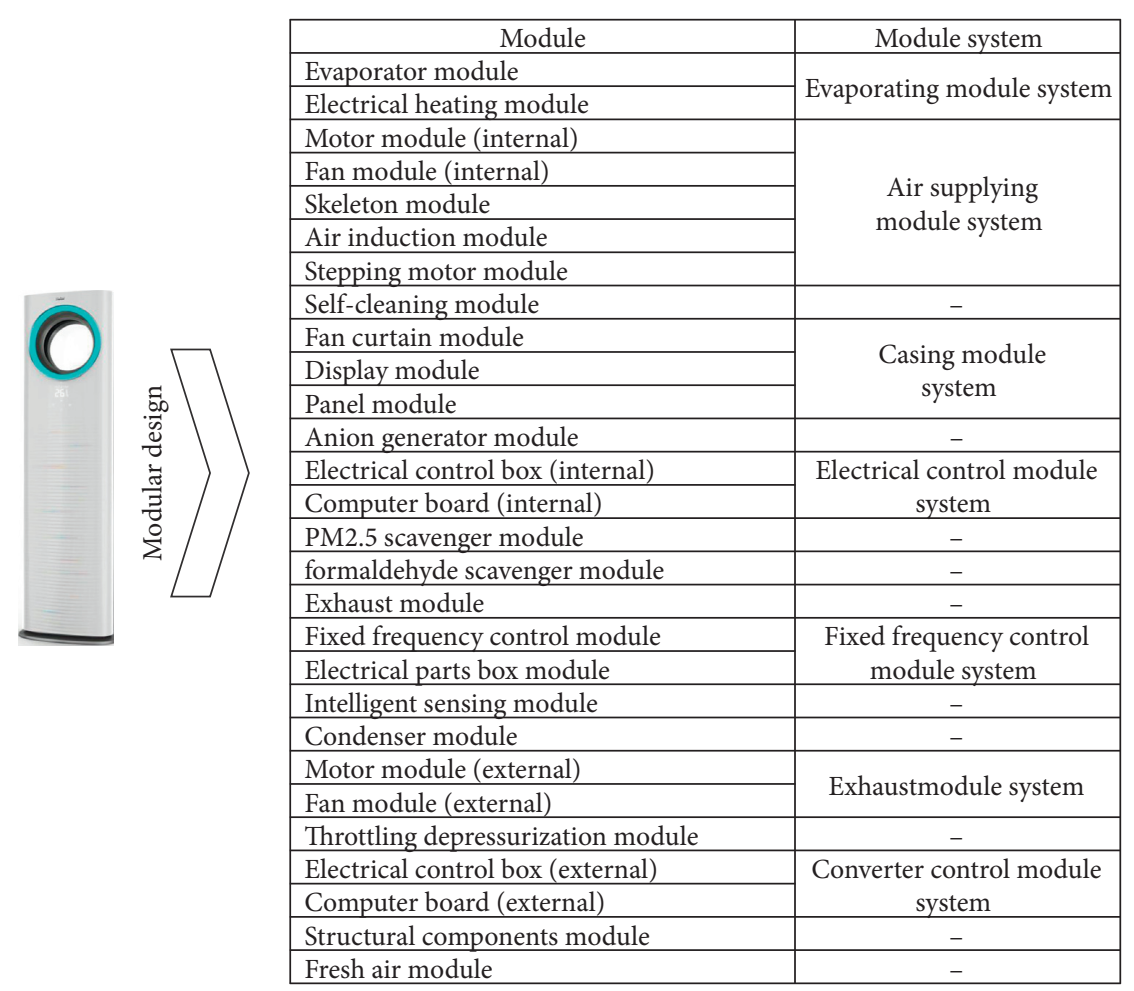

FIgURE 4: The modular product architecture of T-AC.

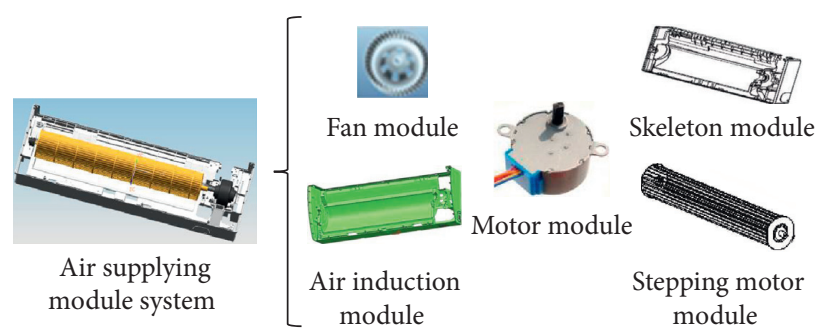

FIgure 5: Composition of the air-supplying module system of T-AC.

performance of innovation resources so as to boost open innovation.

\subsubsection{Barrier-Free Resource Inclusion and Exclusion} Mechanism. In response to Haier's technology requirements, a number of global resources have been included in collaborative innovation, and they are evaluated under equal competition and access conditions. On this basis, a reasonable innovative solution may be proposed by any qualified innovation source in accordance with modular requirements. Previously, the majority of external resources of Haier conditioners were based in China. Starting from 2000, Haier has carried out the innovation strategy of "taking the world as our R\&D center". This has driven the resource integration process of Haier toward globalization. Under the right circumstances, networking tools allow resources in other countries/regions to participate in the fair bidding procedures of Haier and to interact with the company easily. On the other hand, due to the function of the innovation resource filtering mechanism, the innovation resources in the circles of collaborative innovation have to continuously enhance their capabilities and adjust their service strategies based on the dynamic needs of Haier's T-AC. In addition, the ability to secure qualified innovation resources has been included in the assessment of Key Performance Indexes (KPIs) of relevant employees.

3.3.2. Participation Constraint and Incentive Compatibility Mechanism. In order to manage innovation resources within a controllable scope, their behaviors are well regulated so as to avoid possible risks during collaborative innovation. Specifically, strict clauses relating to participation qualifications are defined in contracts between Haier and innovation resources, thus eliminating the possibility of a deliberate withdrawal from cooperation and misconduct. Through the use of incentive compatibility measures, innovation resources are able to 


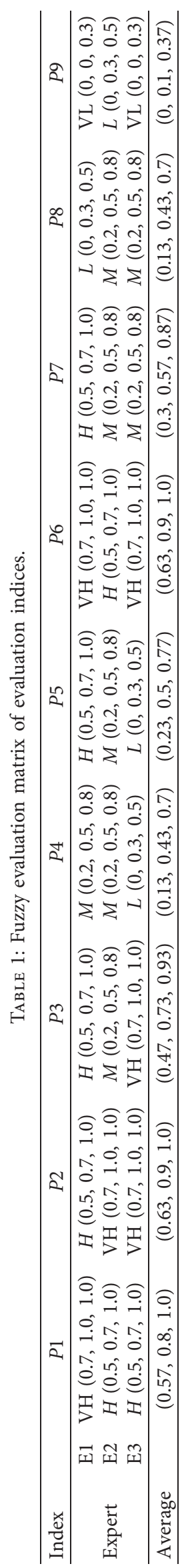


TABLE 2: Fuzzy evaluation matrix of module innovation resources.

\begin{tabular}{|c|c|c|c|c|c|c|c|c|c|}
\hline \multirow{2}{*}{ Resources } & \multicolumn{9}{|c|}{ Indices } \\
\hline & $\mathrm{P} 1$ & $\mathrm{P} 2$ & P3 & $\mathrm{P} 4$ & P5 & P6 & P7 & P8 & P9 \\
\hline M1 & $G, \mathrm{VG}, G$ & $\mathrm{P}, \mathrm{RP}, M$ & VG, GG, VG & $M, P, \mathrm{RG}$ & $\mathrm{RG}, M, M$ & RG, VG, RG & $G, \mathrm{RG}, \mathrm{RG}$ & RG, VG, G & $\mathrm{VG}, G, \mathrm{VG}$ \\
\hline M2 & $\mathrm{RG}, M, R G$ & $M, M, M$ & $G, \mathrm{VG}, G$ & $\mathrm{VP}, \mathrm{VP}, P$ & $P, P, \mathrm{VP}$ & G, RG, RG & $M, \mathrm{RP}, M$ & $\mathrm{RG}, \mathrm{VG}, \mathrm{VG}$ & $G, G, G$ \\
\hline M3 & VG, VG, G & $\mathrm{RP}, P, \mathrm{RP}$ & VG, VG, $G$ & $G, G, G$ & VG, RG, VG & $M, G, M$ & $G, \mathrm{VG}, \mathrm{VG}$ & $\mathrm{RG}, M, \mathrm{RG}$ & $M, M, G$ \\
\hline M4 & $\mathrm{RG}, G, M$ & $M, \mathrm{RP}, \mathrm{RP}$ & $M, M, G$ & $\mathrm{RG}, M, \mathrm{RG}$ & $G, \mathrm{RG}, \mathrm{RG}$ & $M, M, \mathrm{RG}$ & $\mathrm{RG}, \mathrm{G}, \mathrm{VG}$ & $\mathrm{RG}, G, \mathrm{RG}$ & $M, M, G$ \\
\hline M5 & $\mathrm{VP}, \mathrm{VP}, P$ & $\mathrm{RG}, G, \mathrm{VG}$ & $M, M, \mathrm{RG}$ & $\mathrm{RP}, \mathrm{RP}, \mathrm{VP}$ & $\mathrm{RG}, \mathrm{RG}, M$ & $P, M, M$ & $\mathrm{RG}, G, G$ & VG, VG, VG & $P, P, \mathrm{VP}$ \\
\hline M6 & $P, P, \mathrm{VP}$ & $G, \mathrm{RG}, M$ & $\mathrm{RG}, G, \mathrm{RG}$ & $\mathrm{VP}, M, \mathrm{VP}$ & $M, M, \mathrm{RG}$ & $P, M, P$ & RG, RG, G & $G, M, \mathrm{RG}$ & $P, \mathrm{RP}, P$ \\
\hline M7 & $P, \mathrm{VP}, P$ & $\mathrm{RG}, G, M$ & RG, RG, $M$ & $\mathrm{VP}, P, P$ & $\mathrm{RG}, M, \mathrm{RG}$ & $\mathrm{RP}, \mathrm{RP}, \mathrm{RP}$ & $G, G, \mathrm{RG}$ & $G, \mathrm{RG}, \mathrm{RG}$ & $P, P, \mathrm{RP}$ \\
\hline M8 & $\mathrm{RP}, M, P$ & $G, \mathrm{RG}, M$ & $G, G, \mathrm{VG}$ & $M, M, \mathrm{RG}$ & $G, G, \mathrm{VG}$ & $\mathrm{RG}, \mathrm{VG}, G$ & $\mathrm{RG}, G, G$ & $G, M, \mathrm{RG}$ & $M, M, P$ \\
\hline M9 & $M, \mathrm{RG}, M$ & $\mathrm{RG}, M$, RG & $M, G, G$ & $P, P, P$ & $\mathrm{RG}, M, M$ & $G, \mathrm{RG}, \mathrm{VG}$ & $P, \mathrm{VP}, \mathrm{VP}$ & $G, \mathrm{RG}, M$ & $\mathrm{VG}, G, \mathrm{RG}$ \\
\hline
\end{tabular}

TABLE 3: Evaluation of module innovation resources using the distance measurement method.

\begin{tabular}{|c|c|c|c|c|c|c|c|c|c|c|}
\hline$\tau$ & $\mathrm{D}_{\text {max }}, D_{\text {min }}$ & M1 & M2 & M3 & M4 & M5 & M6 & M7 & M8 & M9 \\
\hline \multirow{2}{*}{$\tau=0$} & $D_{\min }$ & 4.1117 & 3.8432 & 4.4135 & 3.9998 & 2.3915 & 2.8137 & 2.9611 & 3.6627 & 3.6723 \\
\hline & $D_{\max }$ & 3.0425 & 3.28148 & 2.7797 & 3.1736 & 4.7060 & 4.2674 & 4.1024 & 3.4875 & 3.4715 \\
\hline \multirow{2}{*}{$\tau=1 / 2$} & $D_{\min }$ & 4.0819 & 3.7919 & 4.3918 & 3.9654 & 2.3414 & 2.7512 & 2.9224 & 3.6277 & 3.6149 \\
\hline & $D_{\max }$ & 3.0214 & 3.2559 & 2.7414 & 3.1539 & 4.7264 & 4.3057 & 4.1215 & 3.4757 & 3.4825 \\
\hline \multirow{2}{*}{$\tau=1$} & $D_{\min }$ & 4.0635 & 3.7882 & 4.3791 & 3.9442 & 2.3092 & 2.7102 & 2.8974 & 3.6059 & 3.5907 \\
\hline & $D_{\max }$ & 3.0140 & 3.2745 & 2.7184 & 3.1430 & 4.7408 & 4.3319 & 4.1349 & 3.4696 & 3.4498 \\
\hline \multirow{2}{*}{$\tau=2$} & $D_{\min }$ & 4.0425 & 3.7633 & 4.3654 & 3.9200 & 2.2705 & 2.6600 & 2.8670 & 3.2810 & 3.5529 \\
\hline & $D_{\max }$ & 3.0000 & 3.2757 & 2.6805 & 3.1281 & 4.7719 & 4.3866 & 4.1636 & 3.7629 & 3.4977 \\
\hline
\end{tabular}

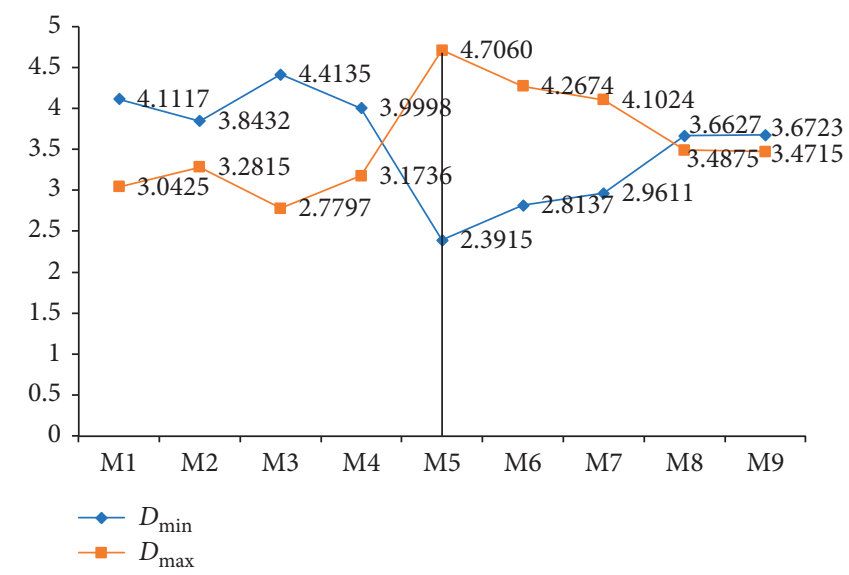

Figure 6: Visualization of the evaluation of module innovation resources at $\tau=0$.

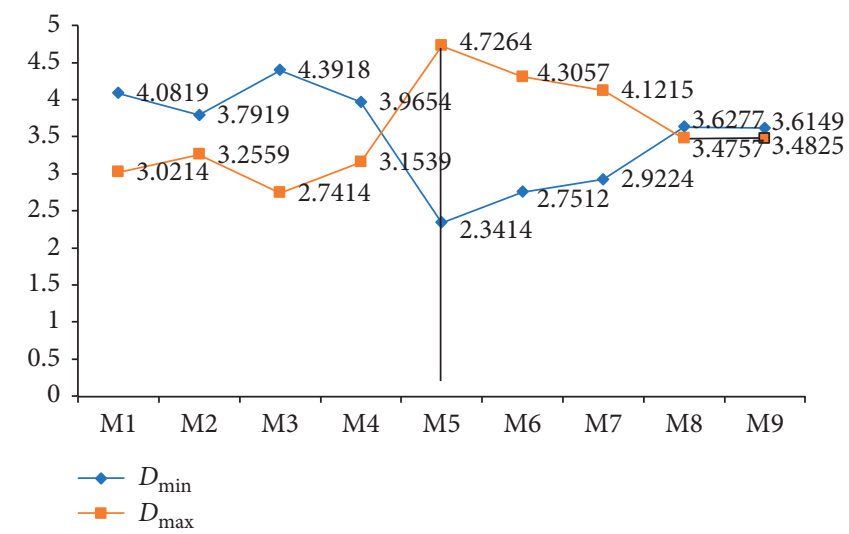

FIGURE 7: Visualization of the evaluation of module innovation resources at $\tau=0.5$. 


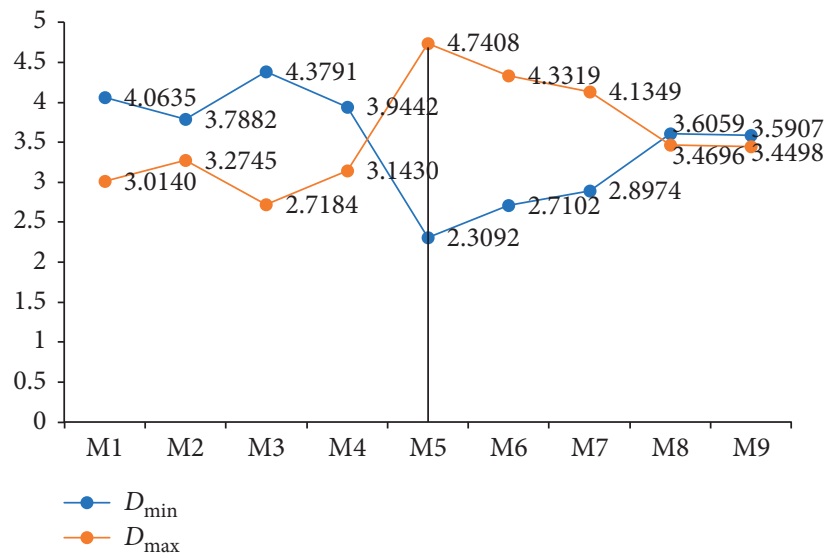

Figure 8: Visualization of the evaluation of module innovation resources at $\tau=1$.

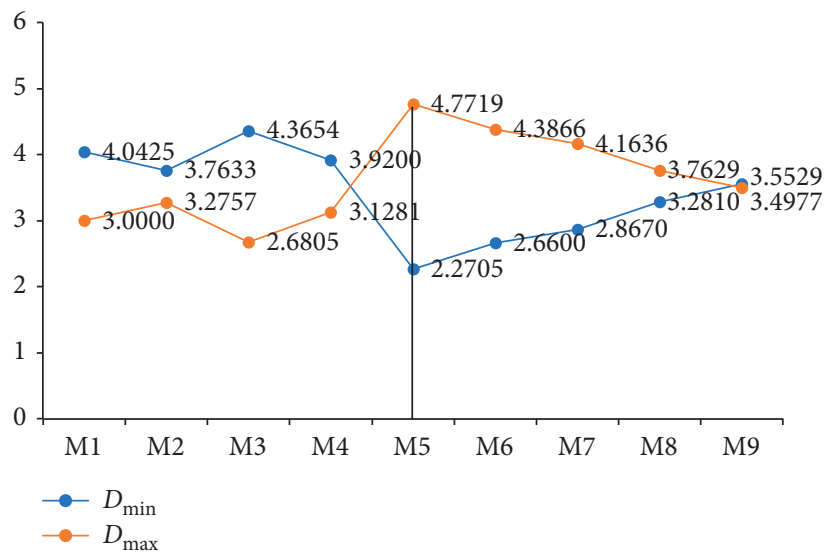

Figure 9: Visualization of the evaluation of module innovation resources at $\tau=2$.

tap their potential effectively for the purpose of profitsharing. For example, a Chinese Southern manufacturer Sunwill was originally only responsible for supplying the fan module of T-AC, but later, it became the designer and supplier of the whole air supply module system thanks to Haier's incentive compatibility mechanism. A purchase order of more than 100,000 units (module systems) per quarter was given to Sunwill together with a contract commission for at least two years. As a result, Sunwill now manages other module suppliers of the air supply module system, including those offering motors and wind deflectors.

3.3.3. Distributed Resource Management Mechanism. The core modules (air supply module system, evaporator module system, etc.) of the modular product architecture of T-AC were developed in the headquarters' $\mathrm{R} \& \mathrm{D}$ center of Haier. At this center, Haier utilizes its R\&D capacities and interacts with innovation resources to strengthen its innovation competence. With high-qualification requirements for standard modules among such innovation resources, resource optimization frequency is low. Haier seeks to establish a strategic cooperation relationship with a number of excellent selected candidates. Individualized modules/systems (formaldehyde elimination module, double-way fresh air module, etc.) are developed in areas close to target markets. The benefits include more synergies with innovation resources, lower cost, and higher service efficiency. To cater for varying user needs, the optimization frequency of the innovation resources in these areas is relatively high.

\section{Conclusions}

4.1. Theoretical Contribution. To fill the gaps in existing studies, the relationship between modularity and open innovation is first analyzed. Module innovation resources in an open environment are then grouped. In order to select qualified innovation resources for core modules of modular product architecture, nine evaluation indices are constructed in this study. Next, a fuzzy distance measurement method is presented to compare fuzzy numbers and decide which innovation resource is optimal. By using a case study of one of Haier Group's modular products, consistent evaluation and selection results are achieved for different decision-making attitudes, proving that the method proposed in this paper is robust. 
4.2. Empirical Conclusions. Based on the case study of the Haier Group, modular product architecture plays a vital role in linking the enterprise's innovation requirements with external innovation resources. Meanwhile, it is discovered that strategic suppliers not only collaborate with Haier in terms of procurement but also actively get involved in core module system innovation. Through the implementation of strategic supplier management mechanisms such as contract binding, dynamic optimization, and big resources in exchange for big resources, a strategic supplier is able to improve its capabilities continuously, thus engaging in open innovation with the company in a win-win context.

\section{Data Availability}

The data used to support the findings of this study are available from the corresponding author upon request.

\section{Conflicts of Interest}

The authors declare that they have no conflicts of interest.

\section{Acknowledgments}

This research was supported by the Chinese National Funding of Social Sciences (19BGL045), Liaoning Public Welfare Research Project (2020JH4/10100023), and the Project is sponsored by Liaoning BaiQianWan Talents Program (2020921084). The authors herewith show appreciation for their support.

\section{References}

[1] D. Vrontis, A. Thrassou, G. Santoro, and A. Papa, “Ambidexterity, external knowledge and performance in knowledgeintensive firms," The Journal of Technology Transfer, vol. 42, no. 2, pp. 374-388, 2016.

[2] M. Candi, D. L. Roberts, T. Marion, and G. Barczak, "Social strategy to gain knowledge for innovation," British Journal of Management, vol. 29, no. 4, pp. 731-749, 2018.

[3] H. Chesbrough, Open Innovation: The New Imperative for Creating and Profiting for Technology, Harvard Business School Press, Cambridge, MA, USA, 2003.

[4] R. W. Schmitt, "Conflict or synergy: University-industry research relations," Accountability in Research, vol. 5, no. 4, pp. 251-254, 2011.

[5] A. Ericsson and G. Erixon, Controlling Design Variants: Modular Product Platforms, American Society of Mechanical Engineers, New York, NY, USA, 1999.

[6] R. Sanchez and J. T. Mahoney, "Modularity, flexibility, and knowledge management in product and organization design," Strategic Management Journal, vol. 17, no. S2, pp. 63-76, 1996.

[7] C. Y. Baldwin and K. B. Clark, "The architecture of participation: Does code architecture mitigate free riding in the open source development model?" Management Science, vol. 52, no. 7, pp. 1116-1127, 2006.

[8] H. J. Wang, J. Cheng, and R. S. Zou, "Study on the coordinating mechanism of knowledge transfer of IURU collaborative innovation under modularity scenario," Studies in Science of Science, vol. 36, no. 7, pp. 1274-1283, 2018.

[9] A. Tiwana, "Does interfirm modularity complement ignorance? A field study of software outsourcing alliances," Strategic Management Journal, vol. 29, no. 11, pp. 1241-1252, 2008.

[10] H. J. Wang and Y. Zhang, "Corporate modularity-based collaborative innovation and innovation resources management: analysis on an exploratory case of haier," Science \& Technology Progress and Policy, vol. 35, no. 21, pp. 97-105, 2018.

[11] H. Chesbrough, S. Kim, and A. Agogino, "Chez Panisse: Building an open innovation ecosystem," California Management Review, vol. 56, no. 4, pp. 144-171, 2014.

[12] J. D. Lewis, "Making strategic alliances work," ResearchTechnology Management, vol. 33, no. 6, pp. 12-15, 1990.

[13] J.-F. Ding and G.-S. Liang, "Using fuzzy MCDM to select partners of strategic alliances for liner shipping," Information Sciences, vol. 173, no. 1-3, pp. 197-225, 2005.

[14] L. Li and Y. Xi, "The design and application study of the evaluation index system of research project collaborative innovation performance," Science \& Technology Progress and Policy, vol. 31, no. 1, pp. 123-129, 2014.

[15] S. Maha and L. Natalia, "Selecting an open innovation community as an alliance partner: looking for healthy communities and ecosystems," Research Policy, vol. 48, no. 8, Article ID 103766, 2019.

[16] J. Jian, M. Wang, L. Li, J. Su, and T. Huang, "A partner selection model for collaborative product innovation from the viewpoint of knowledge collaboration," Kybernetes, vol. 49, no. 6, pp. 1623-1644, 2019.

[17] C. Gu, Y. Wang, and L. Jia, "Ranking fuzzy numbers based on fuzzy distance," Journal of Henan Institute of Education (Natural Science Edition), vol. 23, pp. 17-21, 2014.

[18] Z. Wang, H. Nie, and H. Zhao, "An extended GEDM method with heterogeneous reference points of decision makers and a new hesitant fuzzy distance formula," Computers \& Industrial Engineering, vol. 146, Article ID 106533, 2020.

[19] L. Tran and L. Duckstein, "Comparison of fuzzy numbers using a fuzzy distance measure," Fuzzy Sets and Systems, vol. 130 , no. 3 , pp. 331-341, 2002. 